\title{
Effectiveness of Marketing Promotion Programs: The Case of Texas Citrus
}

\author{
Gary W. Williams ${ }^{1}$, Oral Capps, Jr. ${ }^{2}$, and Marco A. Palma ${ }^{3}$ \\ Department of Agricultural Economics, Texas A \& M University, 458D \\ Blocker Building, 2124 TAMU, College Station, TX 77843-2124
}

Additional index words. advertising, evaluation, grapefruit, oranges, benefit-cost analysis, marketing order

\begin{abstract}
This article analyzes the effectiveness of Marketing Order 906 in promoting Texas grapefruit and oranges and focuses specifically on the answers to two key questions: 1) What have been the effects of the promotion programs funded under Marketing Order 906 on shipments of Texas grapefruit and oranges? 2) What has been the return on the investment made under Marketing Order 906 to promote sales of Texas grapefruit and oranges? The article first provides some background on the Texas citrus promotion program and then develops a seemingly unrelated regression econometric model of Texas grapefruit and orange shipments for the analysis of the effectiveness of the program. The results obtained indicate that the Texas citrus promotion program has been effective in enhancing shipments of Texas grapefruit but not oranges and that the benefits of the promotion efforts have exceeded the costs, at least for grapefruit. Insights are drawn for other commodity promotion programs.
\end{abstract}

The highly perishable nature of many commodities like fruits and vegetables creates a relatively strong tendency toward instability in their markets and, thus, uncertainty in the returns to producers. To help stabilize market conditions for fruit and vegetable products, the U.S. Congress authorized the establishment of marketing orders and agreements through the Agricultural Marketing Agreement of 1937 (7 U.S.C. 601-674). Marketing orders and agreements* are arrangements among producers, handlers, and sometimes processors to work collectively to improve producer income through the orderly marketing of a commodity. Such arrangements usually include provisions for maintaining the high quality of products on the market, standardizing packages and con-

Received for publication 19 June 2007. Accepted for publication 10 Dec. 2007.

The research reported here was conducted under contract with the Texas Valley Citrus Committee (TVCC). We gratefully acknowledge the assistance of both TVCC and TexaSweet Citrus Marketing, Inc. in collecting and compiling a large amount of data relating to Texas citrus shipments and TexaSweet marketing plans and budgets, financial statements, and income and expense. Gratitude is expressed to four anonymous reviewers for their insightful comments.

* Marketing orders are binding on all individuals and businesses classified as "handlers" in a geographic area covered by the order, whereas marketing agreements are binding only on handlers who are voluntary signatories of the agreement.

${ }^{1}$ Professor of Agricultural Economics and Director of the Texas Agribusiness Market Research Center. ${ }^{2}$ Professor of Agricultural Economics and holder of the Southwest Dairy Marketing Endowed Chair.

${ }^{3}$ To whom reprint requests should be addressed; e-mailmapalma@tamu.edu tainers, and regulating the flow of products to the market.

To cover operation and administrative costs, marketing orders are authorized to collect assessment fees on the volume sold by growers. Of the 33 federal marketing orders for fruits, vegetables, nuts, and specialty crops currently in operation, 25 are authorized to use some portion of the assessments collected to fund generic promotion and advertising programs similar to those operated by checkoff programs for many commodities like beef, pork, soybeans, cotton, and others. Only 15 , however, currently fund such programs, including Marketing Order 906 for citrus products (grapefruit and oranges) grown in the Lower Rio Grande Valley of Texas. One of only two federal marketing orders related to citrus, Marketing Order 906 was established in 1960 under part 906 of Chapter 9 of Title 7 (Agriculture) of the Code of Federal Regulations (U.S. Department of Agriculture, 2006b; U.S. Government Printing Office, 2007) and is the only one that is authorized to carry out advertising and promotion programs for citrus products. Marketing Order 905 was established in 1939 for oranges, grapefruit, tangerines, and tangelos grown in Florida.

The primary objective of the citrus promotion program of Marketing Order 906 has been to increase the demand for Texas grapefruit and oranges and, thus, increase the profitability of growing grapefruit and oranges in Texas. As for all such generic commodity promotion programs around the country, the critical concern for growers is whether the investment of the assessments they pay in advertising and other promotional activities is a profitable undertaking (Williams and Capps, 2006). In considering the effectiveness of a commodity promotion program like the one operated under Market- ing Order 906, two general questions must be addressed. First, has the program increased sales, or the volume of shipments as in the case of Texas citrus, over the years? Second, has the program benefitted the growers who pay for the program through assessment fees as intended? Obviously, if the program has not increased sales or shipments, then the program has not benefitted growers. However, even if the program has successfully boosted sales or shipments, the program may still not be of benefit to growers if the total increase achieved in industry revenue has been insufficient to cover the cost required to generate that revenue.

This article analyzes the effectiveness of Marketing Order 906 in promoting Texas grapefruit and oranges and focuses specifically on the answers to two key questions: 1) What have been the effects of the promotion programs funded under Marketing Order 906 on shipments of Texas grapefruit and oranges? (2) What has been the return on the investment made under Marketing Order 906 to promote sales of Texas grapefruit and oranges? Before analyzing the answers to these questions, however, this article first discusses the Texas citrus promotion program as background to the subsequent empirical analysis. Then, after a discussion of the analytical methodology used, the results of the analysis of the two key questions are presented and discussed. Finally, insights are drawn from the analysis for the operation of other commodity promotion programs.

\section{Texas Citrus Promotion Programs}

In the U.S. citrus industry, Florida is known for processed oranges (orange juice), California is known for fresh oranges, and Texas is known for fresh grapefruit. The Texas citrus industry is situated in the southern part of the state, concentrated almost totally in the Lower Rio Grande Valley. The typical Texas grapefruit and orange marketing season begins in October and continues through May with shipments of both citrus fruits typically peaking in the first few months of each calendar year (Jacobs, 1994).

The Texas grapefruit industry has developed around various varieties of seedless, red-fleshed grapefruit with varying degrees of redness in the peel, all of which were developed in Texas from mutations of existing grapefruit. The industry has worked to create a strong brand image for its red grapefruit. The major grapefruit varieties in Texas are Ruby Red, Henderson/Ray, Rio Red, and Star Ruby. Texas markets the Ruby Red and the redder Henderson/Ray varieties under the trademarked name "Ruby-Sweet." The Ruby-Sweet grapefruit are three to five times darker than were the original red grapefruit. They have a yellow skin with a red blush and account for less than $\approx 25 \%$ of Texas grapefruit acreage (Sauls, 2002). The Rio Red and Rio Star varieties, marketed under the trademark "Rio Star," are five times darker than Ruby-Sweets and have peels with an overall red blush. Some less 
red Henderson varieties are marketed under the trademark "Flame" to distinguish them from the Ruby Red varieties and to capitalize on Florida's "Flame" grapefruit, which are related to the Henderson variety.

In contrast to Texas grapefruit, Texas oranges do not have trademarked brand names, primarily because they are not particularly differentiated from the oranges of the same or similar varieties grown in other states. Texas produces various varieties of low-acidity, thin-peel oranges with a yellow peel color and generally light juice color (Sauls, 2002). Texas markets its oranges in three basic categories: 1) navels and early oranges; 2) midseason oranges; and 3) lateseason oranges. Navel oranges normally mature in October and are shipped through January. Their primary use is for gift packs and the fresh market. Most midseason oranges come to market in late November through February. The late-season oranges, primarily Valencia varieties, normally achieve maturity in late January, providing a late-season surge in Texas orange shipments through May. Most Valencias are used for both the fresh market and for processing to upgrade the quality of juice from early oranges.

Established as a means for the Texas citrus industry to regulate the movement of fresh grapefruit and oranges from Hidalgo, Cameron, and Willacy counties in the Lower Rio Grande Valley of Texas, Marketing Order 906 also authorized the assessment and collection of a fee on all cartons of grapefruit and oranges shipped from the three counties to finance the operation and administration of the Order. Under the order, the Texas Valley Citrus Committee (TVCC), composed of nine growers and six handlers, recommends to the U.S. Department of Agriculture for approval the annual assessment rate to be applied to shipments of grapefruit and oranges.

Over the last several years, the annual per carton (7/10 bushel equivalent) assessment has varied from 11.0 cents to 14.0 cents (Fig. 1). Currently, the rate is set at 12.0 cents/carton. Except for a few years of reduced shipments or declines in the assessment rate, annual assessment revenues since the mid-1990s have varied from a low of $\approx \$ 1.0$ million to a high of $\$ 1.2$ million. In 2004/05 and 2005/ 06, however, TVCC decided to reduce the assessment rate from 14.0 cents/carton to 12.0 cents/carton and cut back the budget for promotion leading to a drop in total citrus assessment funds to $\$ 868,000$ and $\$ 914,000$ in 2004/05 and 2005/06, respectively.

Although the majority of the assessment revenue collected each year under Marketing Order 906 is allocated to TexaSweet Citrus Marketing, a nonprofit corporation established under the laws of the state of Texas specifically for the purpose of developing and carrying out promotional programs for Texas grapefruit and oranges under contract with TVCC, the share allocated to TexaSweet has declined since the early 1990s. From a high of $81 \%$ in $1993 / 94$, the allocation to TexaSweet declined to just over half of total

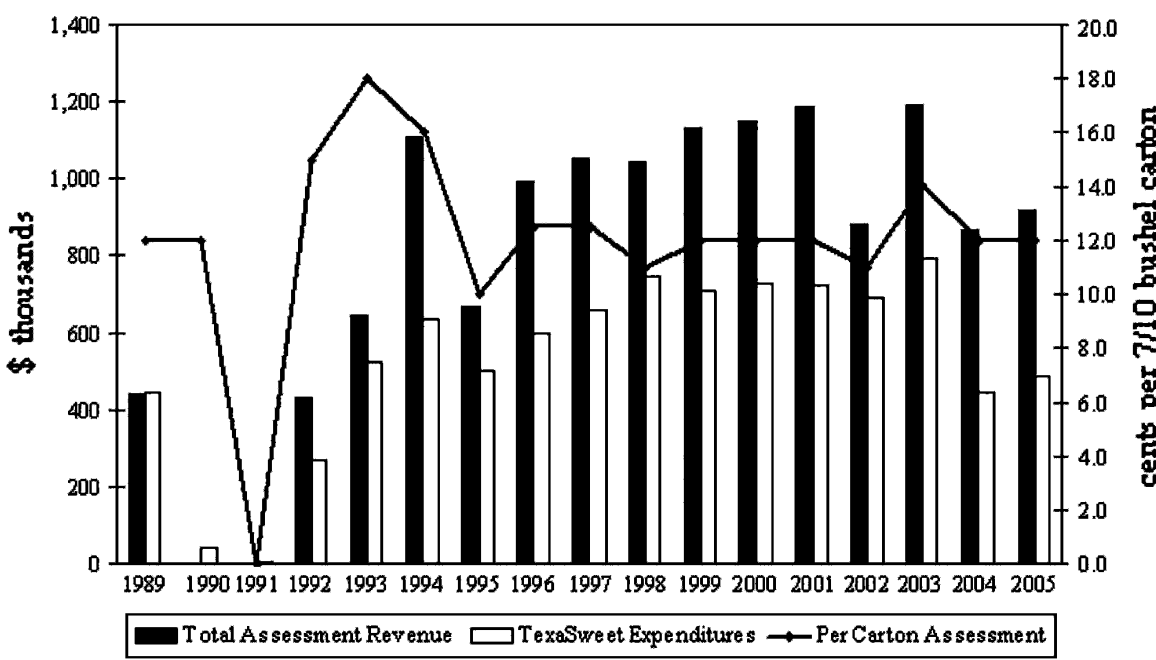

Fig. 1. Total assessments under Marketing Order 906, TexaSweet expenditures, and the per carton assessment, fiscal years 1989 to 2005 . assessment revenue in 2004/05 and in 2005/ 06. The sharp decline in the allocation to TexaSweet in 2004/05 and 2005/06 occurred precisely when the total assessment revenues also declined, which together resulted in a sharp decline in the total dollars allocated to TexaSweet for promotion in those years. From a high of $\approx \$ 795,000$ in $2003 / 04$, allocations to TexaSweet fell to their lowest level in 2004/05 $(\$ 446,000)$ since the Texas freeze years of the early 1990s (Fig. 1).

Texas citrus promotion programs have traditionally included five areas of expenditure: 1) merchandising, 2) public relations, 3) conventions, 4) point-of-purchase (POP) materials, and 5) trade media advertising. Merchandising has included a wide variety of activities, including communications with supermarkets, wholesalers, foodservice companies, and other produce buyers; various promotions to retailers, foodservice, and consumers such as recipe and other contests, giveaways, and incentives; training seminars; direct mailers; development of market pro- files; sponsoring tours of buyers to the Texas citrus growing region; and much more. Public relations has included the development and distribution of kits with various information and promotional materials to retailers and foodservice establishments, the media, food editors, and consumers; media releases to trade magazines; materials to promote special events such as National Grapefruit Month; food writer materials; radio and television show sponsorships; recipe development; bulletins and newsletters; and various public relations events. TexaSweet expenditures on conventions have typically included attending, exhibiting at, and sponsoring a number of produce-related conventions, fairs, programs, and other meetings. POP materials such as kits, recipe materials, retail display bin paper, and banners are developed and distributed to supermarkets, fundraisers, and other locations where Texas citrus is sold. Trade advertising has primarily included placing advertisements in various trade publications (for example, The Packer,

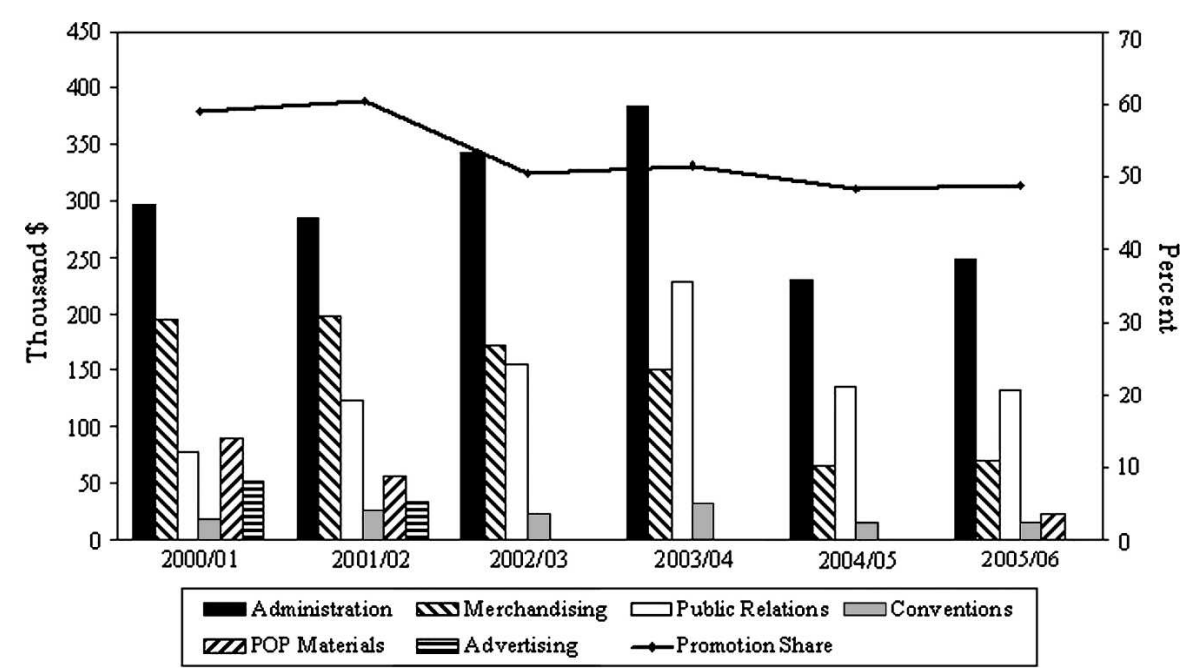

Fig. 2. TexaSweet expenditures by category and share allocated to promotion, fiscal years 2000 to 2005 . 
Progressive Grocer, and Produce Business) during peak periods in the market.

Between 2000/01 and 2005/06, $\approx 54 \%$ of the funds allocated from the citrus assessment was used for promotion programs with the remainder for supporting administrative costs (Fig. 2). Over that period, however, the promotion share of TexaSweet spending declined from $\approx 60 \%$ to a little over $48 \%$. With the decline in total assessment dollars allocated to TexaSweet in 2004/05 and 2005/ 06 , TexaSweet cut administrative costs in an attempt to minimize the impact on the funds available for promotion programs. Nevertheless, the share that TexaSweet allocated to cover administrative costs in those 2 years became larger than the share used for promotion programs for the first time.

Of the funds TexaSweet has spent on assessment-funded promotion programs since $2000 / 01$, over $80 \%$ has been spent on merchandising and public relations activities (Fig. 2 ). Advertising was dropped from the TexaSweet portfolio of promotional tools in 2002/ 03. POP materials were also effectively eliminated as a promotion category after 2001/02 with a small amount spent on this category in $2005 / 06$. Over time, the share of promotion funds allocated to merchandising has declined steadily, whereas the share allocated to public relations has increased.

Although the largest share of TexaSweet promotion expenditures has typically occurred during the Texas citrus marketing year, expenditures have typically spiked in the interseason months of June through September when there are no shipments of citrus. Before the drop in funding for promotion in 2004/05 and 2005/06, much of the interseason promotional expenditures supported merchandising activities. With the drop in funding in 2004/05 and 2005/06, however, promotion expenditures became more evenly distributed throughout the year and interseason promotion expenditures focused on public relations activities.

\section{Materials and Methods}

Early efforts to measure the demand effects of the various commodity promotion programs around the country relied largely on anecdotal evidence and simple comparisons of gross investments in promotion and gross changes in sales. During periods of rapidly expanding markets and rising prices, this approach tends to yield some persuasive stories and even more impressive upwardsloping graphical relationships between promotion expenditures and sales.

The problem with this approach, however, is that various factors other than the promotion program affect the volume and value of commodity sales such as relative price changes, agricultural policies, changes in incomes, population growth, competition from other products, supply disruptions, and consumer health concerns and demographics, just to name a few. The problem becomes all too apparent in years when markets turn down and prices drop. Program managers find that taking credit for rising demand and prices in good years forces them to take the blame for declining demand and prices in bad years.

Over the years, increasingly sophisticated statistical methods have been developed to isolate and measure the unique contribution of promotion programs to the performance of the sales of the commodity being promoted. Most common has been the use of econometric regression techniques and models to statistically disentangle the effects of promotion program activities on commodity sales and demand from those of other market forces. The process usually requires a large amount of historical data on not only the sales of the product and advertising expenditures over time, but also data related to the many other relevant market forces that might have affected sales over the same period. The application of the statistical technique to the data allows for the measurement of the unique contribution of each market force considered, including promotion, to the change in sales observed over the years.

Even if the statistical analysis indicates that promotion programs have had a positive and statistically significant effect on market sales, however, the question remains as to whether the increase has been large enough to cover the cost of the program. For that reason, the next step in the measurement process is to use the statistical results to calculate some aggregate measure of the effectiveness of the promotion expenditures. The most commonly reported measure is the benefit-cost ratio (BCR).

Pagán et al. (2001) published the only other analysis of Texas citrus promotion programs. They used a bivariate vector autoregressive model using weekly data on the dollar value of trade media advertising expenditures and carton equivalent shipments over the 1993/94 to 1999/00 marketing years. They found that increases in advertising expenditures tended to increase orange shipments relatively quickly - within 1 week of the expenditures. On the other hand, they found that advertising had an even more immediate and relatively larger effect on grapefruit shipments. They also found that the full effect of the advertising dissipated after 3 weeks. Unfortunately, Pagán et al. (PSS) considered only advertising expenditures in their study rather than the full range of promotional activities carried out by TexaSweet. As discussed earlier, TexaSweet discontinued expenditures on advertising in $2002 / 03$. Also, PSS failed to report how responsive Texas citrus sales were over the $1993 / 94$ to $1999 / 00$ period to changes in the advertising expenditures. Moreover, although the PSS study results are consistent with a conclusion that TexaSweet advertising expenditures have an effect on Texas grapefruit and orange sales, the study fails to provide any measure of the benefits or the ratio of benefits to costs related to TexaSweet advertising.

This analysis considers the more recent period of $2000 / 01$ to $2005 / 06$. In contrast to the PSS study, this analysis relies on the more well-accepted structural econometric modeling approach that provides measures of the responsiveness of citrus shipments to changes in promotion expenditures and makes the calculation of the benefit-cost ratios associated with the promotion program possible. In addition, rather than considering only the trade media advertising expenditures as done by PSS, this analysis considers the effectiveness of all expenditures by TexaSweet to promote Texas citrus.

To measure the responsiveness of citrus shipments to changes in Texas citrus promotion expenditures and estimate the BCR, a seemingly unrelated regression (SUR) econometric model consisting of two equations is developed and used to explain the effect of promotion expenditures on: 1) Texas grapefruit shipments and 2) Texas orange shipments. Because the correlation of factors embedded in the disturbance terms, which are common to both equations, is taken into account, the SUR estimator can provide more precise estimates of the structural parameters of the two equations than might be achieved by estimating the parameters of each equation separately with the ordinary least squares (OLS) estimator as is typically done (Zellner, 1962).

The process of statistically isolating the effects of a promotion program on market variables like citrus shipments requires the measurement of the effects of other factors that also may affect those same market variables. Thus, a critical step in the evaluation of any commodity promotion program is to identify the other important factors that affect the market and then to obtain the data related to those factors.

In this analysis, the primary factors other than promotion considered to be potential drivers of Texas citrus shipments include the price of grapefruit, the price of oranges, market season, seasonality, inflation, and stickiness or inertia in citrus shipments. In essence, the statistical analysis isolates and measures the specific effects of all these factors, including promotion, on citrus shipments. The measured effects of promotion, then, are used to calculate the "payoff ratio," more commonly known as the BCR, of the expenditures designed to enhance the shipments of Texas citrus. This analysis specifically focuses on explaining changes in monthly shipments of grapefruit, oranges, and citrus from the Rio Grande Valley over the 2000/01 through the 2005/06 marketing years, 6 marketing years in total.

The general form of the two econometric equations used for this analysis is expressed as:

$$
C_{i}=f\left(P_{i} / I, E / I, D_{i}, S_{i}, C_{i t-1}\right)
$$

where $\mathrm{i}=$ grapefruit, oranges, and all variables are assumed to be subscripted with $t$ corresponding to the current month unless otherwise indicated; $\mathrm{C}=$ monthly shipments; $\mathrm{P}=$ packinghouse door price; $\mathrm{I}=$ consumer price index; $\mathrm{E}=$ TexaSweet promotion expenditures; $\mathrm{D}=$ indicator variable representing 
potential differences in production/shipping seasons resulting from events like weather or diseases; and $\mathrm{S}=$ indicator variable representing seasonality within each shipping season.

Grapefruit and orange shipment data are measured as "Texas boxes" ( $80 \mathrm{lb} / \mathrm{box}$ for grapefruit and $85 \mathrm{lb} /$ box for oranges). The promotion expenditure data used in the analysis were provided by TexaSweet Citrus Marketing, Inc. as monthly totals by category of expenditure. The citrus shipment data used were provided by the TVCC as weekly observations. The monthly data on Texas citrus prices came from the U.S. Department of Agriculture (2006a). For the analysis, the citrus prices and the promotion expenditure data were deflated by the consumer price index to form "real" prices and "real" promotion expenditures, respectively, to account for the effects of inflation.

To match the periodicity of the monthly shipment and price data with the weekly promotion data for analysis, the weekly shipment data were aggregated into monthly observations. Seasonality as well as the effects of weather and other events in different shipping/marketing seasons are modeled using monthly indicator (dummy) variables. Finally, the stickiness or inertia in shipments (often referred to as the "habit persistence" of buyers) is represented with a 1-month lag of shipments in each equation.

Although the analysis covered 6 marketing years with potentially 72 monthly observations, because shipments only occur for 8 to 10 months of the year beginning in approximately September or October of each year, only 49 monthly observations of shipments and prices of Texas citrus over the $2000 / 01$ to $2005 / 06$ period were available for the analysis. Despite the 2- to 4-month hiatus in Texas citrus shipments each year, TexaSweet runs a year-round promotion program and, therefore, finances promotion activities in all 12 months of the year, yielding a total of 72 monthly observations on promotion expenditures over the period of analysis. The monthly promotion expenditures were seasonally adjusted using the X12 procedure developed originally by the U.S. Census Bureau (Findley et al., 1998).

A key issue in the econometric analysis was how to match up the year-round, seasonally adjusted promotion expenditures with the 8- to 10-month marketing season of citrus shipments. Recall from the earlier discussion that interseason promotion expenditures by TexaSweet each year are used primarily to develop materials and otherwise prepare for the following shipping season. Consequently, for the interseason months when there were no shipments (typically, June, July, August, and September), promotion expenditures were added together and then apportioned across the remaining months of each marketing year based on the monthly shares of total shipments in each year. The result is 49 monthly observations of promotion expenditure data in which, for a given shipping season, the expenditure data in a given month are the sum of the actual expenditures made in that month plus the aforementioned apportioned sum. Recall that these expenditures were seasonally adjusted initially to remove any confounding of seasonality in citrus shipments from seasonality in advertising and promotion expenditures. Finally, the seasonally adjusted advertising and promotion expenditures were adjusted further for inflation.

For estimating the parameters of the two equations comprising the SUR model, the relationship among the variables was assumed to be linear in logarithms. This functional form assumes that the own-price and promotion elasticities of the demand for Texas citrus are constant over the sample period. Also, the use of the logarithmic transformation ensures that the usual assumption of diminishing marginal returns with respect to promotion expenditures is met.

To account for potential carryover effects in the Texas citrus promotion program, we use the polynomial distributed lag (PDL) procedure often used in studies of commodity promotion effects (see, for example, Clarke, 1976; Forker and Ward, 1998; Lee and Brown, 1992; Williams et al., 2002). The attractive features of the PDL procedure include: 1) a flexible representation of the lag structure allowing for the possibility of humped-shaped or monotonically declining lag weight distributions and 2) a parsimonious representation of the lag structure. The search for the polynomial degree and lag length associated with the carryover effects involves a series of regression estimations with various lags. We allow for carryover effects of up to 8 months in the analysis, consistent with the length of the shipping season for citrus. Second- and third-degree polynomials are considered for both equations for grapefruit shipments and orange shipments estimated with SUR. Also, based on the Akaike Information Criterion (AIC) and the Schwarz Information Criterion (SIC) statistics, both head and tail end point restrictions are used in both models estimated (grapefruit and oranges).

The AIC and SIC statistics also indicate that there are no carryover effects associated with Texas citrus promotion expenditures in either of the two equations estimated with SUR. This result also is consistent with the findings of the PSS study (2001) for the 1993/ 94 through 1999/00 shipping seasons. Consequently, only the contemporaneous effects of the promotion expenditures are considered in the analysis.

Based on the AIC and SIC statistics, we also test various price expectation mechanisms involving different lag lengths on prices and find that for grapefruit, only the contemporaneous effects of the respective prices must be considered-a sort of rational expectations result. That is, monthly purchase decisions of Texas grapefruit buyers are found to be unaffected by changes in the grapefruit price in recent months. Rather, their buying decisions are affected only by the price in the month in which they purchase the grapefruit. For oranges, however, we find that the impact of price on shipments is not felt all at once but is spread over a period of 4 months. That is, the orange equation as estimated captures the effects of the real price of oranges on shipments through the use of a second-degree polynomial-distributed lag with a lag length of 4 months. Thus, monthly purchase decisions of Texas orange buyers are affected by how orange prices have changed over the most recent 4-month period.

\section{Results of Econometric Analysis}

For estimating the parameters of both equations (grapefruit and oranges), the empirical analysis considers Texas citrus promotion expenditures over the entire 2000/01 through 2005/06 marketing years. The basic analytical question is whether Texas citrus promotion expenditures have effectively increased Texas shipments of grapefruit and oranges.

Because the assessment funds allocated for promotion programs declined markedly after the 2003/04 marketing year, the econometric analysis provides the opportunity to consider the implications for Texas citrus shipments of inconsistency in promotion funding. Consequently, the parameters of the two equations in the SUR model are also estimated for just the $2000 / 01$ to $2003 / 04$ period before the substantial reduction in promotion expenditures. A comparison of the two sets of parameters for each equation provides some insight into the change in effectiveness of promotion after a reduction in funding.

The empirical results for the grapefruit shipment and orange shipment equations estimated using the SUR estimator are exhibited in Tables 1 and 2, respectively. All estimated coefficients for both equations over both time periods considered (2000/01$2005 / 06$ and 2001-2003/04) have the expected signs and most are statistically significant at the 0.01 level. The goodnessof-fit (R-squared) for both equations for both time periods is 0.90 or above. The nonzero elements of the residual correlation matrices for both time periods offer evidence that the use of SUR is statistically superior to estimating an equation for each citrus fruit separately using OLS. Also, the use of SUR offers gains in statistical efficiency in the estimation of the structural parameters. That is, the SES of the parameters estimated with the SUR estimator are lower than comparable SES generated from estimating each equation individually with OLS.

Seasonal differences by month within shipping/marketing seasons are evident for both grapefruit and oranges in both time periods (Tables 1 and 2). Shipment volume for grapefruit is highest in October, November, and December and lowest in April and May (Table 1). Shipment volume for oranges is highest in December and January and lowest in April and May (Table 2). Differences in shipment volume also are evident 
Table 1. Equation for grapefruit shipments from SUR model. ${ }^{z}$

\begin{tabular}{|c|c|c|c|c|}
\hline \multirow[b]{3}{*}{ Variable } & \multicolumn{4}{|c|}{ Dependent variable: LN(GSHIPMENTS) } \\
\hline & \multicolumn{2}{|c|}{$2000 / 01-2005 / 06$} & \multicolumn{2}{|c|}{$2000 / 01-2003 / 04$} \\
\hline & Coefficient & SE & Coefficient & SE \\
\hline$\overline{\mathrm{LN}(\mathrm{GPRICE})}$ & $-0.7624 * * *$ & 0.1806 & $-0.7918 * * *$ & 0.1559 \\
\hline LN(CPROMOA) & $0.2645 * * *$ & 0.1066 & $0.3008 * * *$ & 0.0894 \\
\hline LN(GSHIPMENTS $)_{\mathrm{t}-1}$ & 0.1473 & 0.1338 & 0.1751 & 0.1569 \\
\hline Jan & $2.2914 * * *$ & 0.3103 & $2.1661 * * *$ & 0.2490 \\
\hline Feb & $2.0129 * * *$ & 0.3035 & $1.9732 * * *$ & 0.2381 \\
\hline Mar & $1.9110 * * *$ & 0.2903 & $1.8011 * * *$ & 0.2246 \\
\hline Apr & $1.4184 * * *$ & 0.2875 & $1.4671 * * *$ & 0.2206 \\
\hline May & 0.2203 & 0.2759 & $0.5208 * * *$ & 0.2053 \\
\hline Oct & $2.6800 * * *$ & 0.4047 & $2.8995 * * *$ & 0.3437 \\
\hline Nov & $2.4895 * * *$ & 0.3243 & $2.5336 * * *$ & 0.2565 \\
\hline Dec & $2.5032 * * *$ & 0.3115 & $2.4317 * * *$ & 0.2454 \\
\hline Season 2000 & $7.3302 * * *$ & 2.0982 & $6.5953 * * *$ & 2.1521 \\
\hline Season 2001 & $7.6385 * * *$ & 2.1107 & $6.8868 * * *$ & 2.1636 \\
\hline Season 2002 & $7.2185 * * *$ & 2.1060 & $6.4625 * * *$ & 2.1555 \\
\hline Season 2003 & $7.3858 * * *$ & 2.0975 & $6.6350 * * *$ & 2.1433 \\
\hline Season 2004 & $8.2431 * * *$ & 2.0646 & & \\
\hline Season 2005 & $8.1228 * * *$ & 2.0842 & & \\
\hline $\mathrm{R}^{2}$ (adjusted $\mathrm{R}^{2}$ ) & 08988 & & 0.935 & \\
\hline Durbin-Watson & & & & \\
\hline Durbin-h & & & & \\
\hline No. of observations & & & & \\
\hline
\end{tabular}

${ }^{{ }^{z} \text { GSHIPMENTS }}=$ monthly Texas shipments of grapefruit, boxes; GPRICE $=$ Texas grapefruit price (fresh and processed), inflation-adjusted, packinghouse delivered (PHD; \$/box); CPROMOA = seasonally adjusted, inflation-adjusted, monthly TexaSweet promotion expenditures of citrus assessment funds; Jan., Feb., Mar., Apr., May, Oct., Nov., Dec. = indicator variables for corresponding month in which grapefruit shipments occurred where Jan $=1$ if the month is January and 0 otherwise, etc.; Season $200 \mathrm{i}$ (where $\mathrm{i}=1,2$, $3,4,5)=$ indicator variables for corresponding season of grapefruit shipments where the variable $=1$ if the season is 2001 and 0 otherwise, and so on.

${ }^{y}$ The Durbin-h statistic is not particularly meaningful when the coefficient of the lagged dependent variable is not statistically significant as is the case here.

${ }^{*},{ }^{* *},{ }^{* * *}$ The estimated coefficient is statistically different from zero at the $10 \%, 5 \%$, and $1 \%$ hypothesis levels, respectively.

SUR $=$ seemingly unrelated regression.

Table 2. Equation for orange shipments from SUR model. ${ }^{\mathrm{z}}$

\begin{tabular}{|c|c|c|c|c|}
\hline \multirow[b]{3}{*}{ Variable } & \multicolumn{4}{|c|}{ Dependent variable: LN(OSHIPMENTS) } \\
\hline & \multicolumn{2}{|c|}{$2000 / 01-2005 / 06$} & \multicolumn{2}{|c|}{$2000 / 01-2003 / 04$} \\
\hline & Coefficient & $\mathrm{SE}$ & Coefficient & $\mathrm{SE}$ \\
\hline$\overline{\mathrm{LN}(\mathrm{OPRICE})}$ & $-0.0226^{* * *}$ & 0.0074 & $-0.0311^{* * *}$ & 0.0076 \\
\hline LN(CPROMOA) & 0.0695 & 0.1213 & 0.1383 & 0.1026 \\
\hline LN(OSHIPMENTS $)_{t-1}$ & $0.1518 * *$ & 0.0723 & 0.0921 & 0.0645 \\
\hline Jan & $5.9346 * * *$ & 0.3217 & $6.1972 * * *$ & 0.2377 \\
\hline $\mathrm{Feb}$ & $5.5070 * * *$ & 0.3153 & $5.6255^{* * *}$ & 0.2264 \\
\hline Mar & $5.1405 * * *$ & 0.3115 & $5.0734 * * *$ & 0.2341 \\
\hline Apr & $4.1426 * * *$ & 0.3047 & $4.2803 * * *$ & 0.2217 \\
\hline May & $3.3481 * * *$ & 0.2862 & $3.5664 * * *$ & 0.1962 \\
\hline Oct & $5.6889^{* * *}$ & 0.3064 & $5.7511^{* * *}$ & 0.2352 \\
\hline Nov & $5.5548 * * *$ & 0.3091 & $5.8567 * * *$ & 0.2202 \\
\hline Dec & $6.1057 * * *$ & 0.3121 & $6.3755^{* * *}$ & 0.2235 \\
\hline Season 2000 & $5.1787 * * *$ & 1.3419 & $5.2551 * * *$ & 1.1870 \\
\hline Season 2001 & $5.2987 * * *$ & 1.2932 & $5.4196 * * *$ & 1.1024 \\
\hline Season 2002 & $5.2331 * * *$ & 1.3059 & $5.3651 * * *$ & 1.1136 \\
\hline Season 2003 & $5.3273 * * *$ & 1.3050 & $5.5040 * * *$ & 1.1037 \\
\hline Season 2004 & $5.6436^{* * *}$ & 1.2251 & & \\
\hline Season 2005 & $5.3013^{* * *}$ & 1.2531 & \multirow{2}{*}{\multicolumn{2}{|c|}{$0.9835(0.9671)$}} \\
\hline $\mathrm{R}^{2}\left(\right.$ adjusted $\mathrm{R}^{2}$ ) & \multicolumn{2}{|c|}{$0.9572(0.9327)$} & & \\
\hline Durbin-Watson & \multicolumn{2}{|c|}{1.5095} & \multicolumn{2}{|c|}{1.5121} \\
\hline Durbin-h & \multicolumn{2}{|c|}{1.9815} & \multicolumn{2}{|c|}{$1.4821^{y}$} \\
\hline No. of observations & \multicolumn{2}{|c|}{48} & \multicolumn{2}{|c|}{32} \\
\hline
\end{tabular}

${ }^{\text {zOSHIPMENTS }}=$ monthly Texas shipments of oranges, boxes; LNOPRICE $=5 *$ LN $($ OPRICE $)+$ $8 * \mathrm{LN}(\text { OPRICE })_{\mathrm{t}-1}+9 * \mathrm{LN}(\text { OPRICE })_{\mathrm{t}-2}+8 * \mathrm{LN}(\text { OPRICE })_{\mathrm{t}-3}+5 * \mathrm{LN}(\text { OPRICE })_{\mathrm{t}-4}$ where OPRICE $=$ Texas orange price, inflation-adjusted, packinghouse-delivered (PHD; \$/box); CPROMOA = seasonally adjusted, inflation-adjusted, monthly TexaSweet promotion expenditures of citrus assessment funds; Jan, Feb, Mar, Apr, May, Oct, Nov, Dec = indicator variables for corresponding month in which orange shipments occurred where Jan $=1$ if the month is January and 0 otherwise, etc.; Season $200 \mathrm{i}$ (where $\mathrm{i}=1,2$, $3,4,5)=$ indicator variables for corresponding season of grapefruit shipments where the variable $=1$ if the season is 2001 and 0 otherwise, etc.

${ }^{\mathrm{y}}$ The Durbin-h statistic is not particularly meaningful when the coefficient of the lagged dependent variable is not statistically significant.

${ }^{*},{ }^{* *},{ }^{* * *}$ The estimated coefficient is statistically different from zero at the $10 \%, 5 \%$, and $1 \%$ hypothesis levels, respectively.

SUR $=$ seemingly unrelated regression. across shipping/marketing seasons for both grapefruit and oranges in both time periods (Tables 1 and 2). Note that the coefficient for the 2004 season is the highest in both equations likely reflecting the effects of the hurricanes in Florida during that season on shipments of Texas oranges and grapefruit.

All estimated own-price elasticities for both grapefruit and oranges are in the inelastic range. The own-price elasticity for grapefruit shipments is estimated to be -0.76 over the full time period of analysis and -0.79 over the first three shipping seasons (Table 1). For orange shipments, the estimated short-run own-price elasticity over the full period of analysis is -0.11 , which is the estimated coefficient for the orange price variable multiplied by 5 (see footnote to Table 2). The estimated long-run own-price elasticity for orange shipments is -0.79 . The estimated short-run and long-run own-price elasticities for orange shipments over the first three shipping seasons, -0.16 and -1.09 , respectively, are somewhat higher than is the case for the full time period of analysis.

The promotion elasticity for grapefruit shipments over the full time period of analysis is estimated to be 0.264 , meaning that a $10 \%$ increase in promotion funding increases Texas grapefruit shipments by $2.6 \%$ (Table 1). A somewhat higher grapefruit promotion elasticity over the first 3 years of 0.301 indicates that the marginal effect of expenditures on grapefruit shipments declined when funding was reduced in 2004/05 and 2005/06

In contrast to grapefruit, the estimated effects of promotion expenditures on shipments of Texas oranges are not statistically different from zero in either of the two time periods considered (Table 2). In other words, promotion expenditures were found to be ineffective in shifting out the demand for Texas oranges. Thus, although promotion has had a tendency to make the demand for Texas oranges more price-inelastic and, therefore, enhance buyer loyalty, promotion has not been effective in shifting out the demand for Texas oranges.

\section{Discussion and Implications for the Texas Citrus Industry}

The econometric results can be used to analyze the two key questions that are the specific focus of this study. The analysis of the first question focuses on whether the expenditures of citrus assessment revenues under Marketing Order 906 to promote Texas citrus have effectively and consistently increased the shipments of Texas grapefruit and oranges over the 6-year period of 2000/ 01 to $2005 / 06$. The question of the return to Texas citrus promotion activities is analyzed in a benefit-cost framework in which BCRs related to Texas citrus promotion are calculated as the increase in dollar sales and volume of shipments per promotion dollar spent over the two time periods analyzed. 
Using the estimated promotion elasticities, the change in Texas grapefruit and orange shipments effected by the Texas citrus promotion program can be calculated as:

$$
\mathrm{C}_{\mathrm{i}}^{\mathrm{A}}-\mathrm{C}_{\mathrm{i}}^{\mathrm{Z}}=\mathrm{e}_{\mathrm{i}} \mathrm{C}_{\mathrm{i}}^{\mathrm{A}}
$$

where $\mathrm{i}=$ grapefruit, oranges, and all variables (except e) are assumed to subscripted with $t$ corresponding to the current month as before; $\mathrm{C}^{\mathrm{A}}=$ actual shipments; $\mathrm{C}^{\mathrm{Z}}=$ level of shipments that would have occurred with no promotion expenditures; and $\mathrm{e}=$ estimated promotion elasticity.

For grapefruit, the calculation given by Eq. (2) indicates that promotion expenditures added 198,915 boxes monthly to shipments for a total of $9,746,832$ boxes over the 2000/ 01-2005/06 shipping seasons that would have not been grown or shipped in the absence of the Texas citrus promotion program (Table 3). In terms of additional grapefruit industry revenues generated by the promotion program, the increased shipments translate into an average of over $\$ 1.1$ million per month for a total of over $\$ 56.1$ million over the six seasons.

In contrast, the statistically insignificant promotion elasticity estimated for orange shipments indicates that promotion expenditures have had no statistically discernible effect on orange shipments or, therefore, industry revenues. This result is not surprising for several reasons. First, as mentioned earlier, Texas oranges are not particularly differentiated from the oranges of the same or similar varieties grown in other states. Compared with Texas grapefruit, Texas oranges are more of a generic commodity so that promotion efforts are less likely to increase the demand for Texas oranges than for Texas grapefruit. Also, given the efforts of states like California to differentiate their fresh oranges in the minds of consumers and the much larger promotion budgets and programs they operate, Texas promotion is unlikely to have a measurable effect on orange shipments. In their study, PSS also found a much smaller effect of advertising on Texas orange shipments than was found for grapefruit. At the same time, a review of the annual TexaSweet promotion plans for the 2000/01 through 2005/06 marketing years reveals that grapefruit have been nearly the exclusive program focus of the specific objectives and strategies of their promotion programs each year.

Over the last two seasons of the study period (2004/05 and 2005/06) when the budget for promotional activities was cut by an annual average of nearly $44 \%$, the reduction in promotion funding limited the impact of promotion on the demand for Texas grapefruit. From an average annual impact of nearly 2.0 million boxes in the first three seasons, the calculated annual impact of the Texas citrus promotion program dropped by more than half to an average of $\approx 876,000$ boxes in the last two seasons (Table 3). However, the average market price per box jumped dramatically between the first three seasons and the last two seasons by almost fourfold from $\$ 3.89$ to $\$ 14.26$ as a result of market forces, including the hurricanes and diseases that plagued the Florida grapefruit industry in those two seasons. As a consequence, the additional earnings generated annually by the promotion programs increased in the last two seasons despite the fewer boxes added by promotion in each of those two seasons.

Although the econometric results demonstrate that the Texas citrus promotion program over the last 6 years has effectively increased the demand for Texas grapefruit, the critical question is whether the cost of achieving the increase has been less than the revenues generated by the increased demand. To explore this question, the statistical results are used to calculate a BCR as a measure of the cost-effectiveness of the Texas citrus promotion program. The standard BCR is calculated as the sum of the net revenues generated (that is, the gross revenues from additional shipments [R] minus the cost of the promotion [E]) over some time period divided by the sum of the cost of the promotion program over that time period:

$$
\text { BCR }=\frac{\sum_{t=1}^{T}\left(R_{t}-E_{t}\right)}{\sum_{t=1}^{T} E_{t}}
$$

where $\mathrm{t}$ refers to a particular month and $\mathrm{T}$ is the total number of months in the analysis. If the calculated BCR is greater than one, the promotion program can be considered to be "effective" because more than one dollar in shipment revenue is generated for every dollar spent. On the other hand, if the calculated BCR is less than one, the program would be considered to be "ineffective."

Using Eq. (2) to calculate the additional grapefruit shipments and the corresponding industry revenue $(\mathrm{R})$ as a result of the Texas citrus promotion, Eq. (3) is then used to calculate the corresponding grapefruit BCR at the packinghouse door level. Given that the grapefruit grower share of packinghouse door dollars averaged $71.0 \%$ over the six shipping seasons of 2000/01-2005/06, the grapefruit BCR for the Texas citrus promotion program at the grower level is calculated assuming that the grapefruit grower share of additional packinghouse door revenue is $\approx 70 \%$.

One problem with the BCR as a measure of "effectiveness" is that for a given expenditure of promotion funds, the BCR in one period can be higher than the BCR in another period simply because the market price is different in the two periods. For example,

Table 3. Benefit-cost analysis of Texas citrus promotion, 2000/2001-2005/2006.

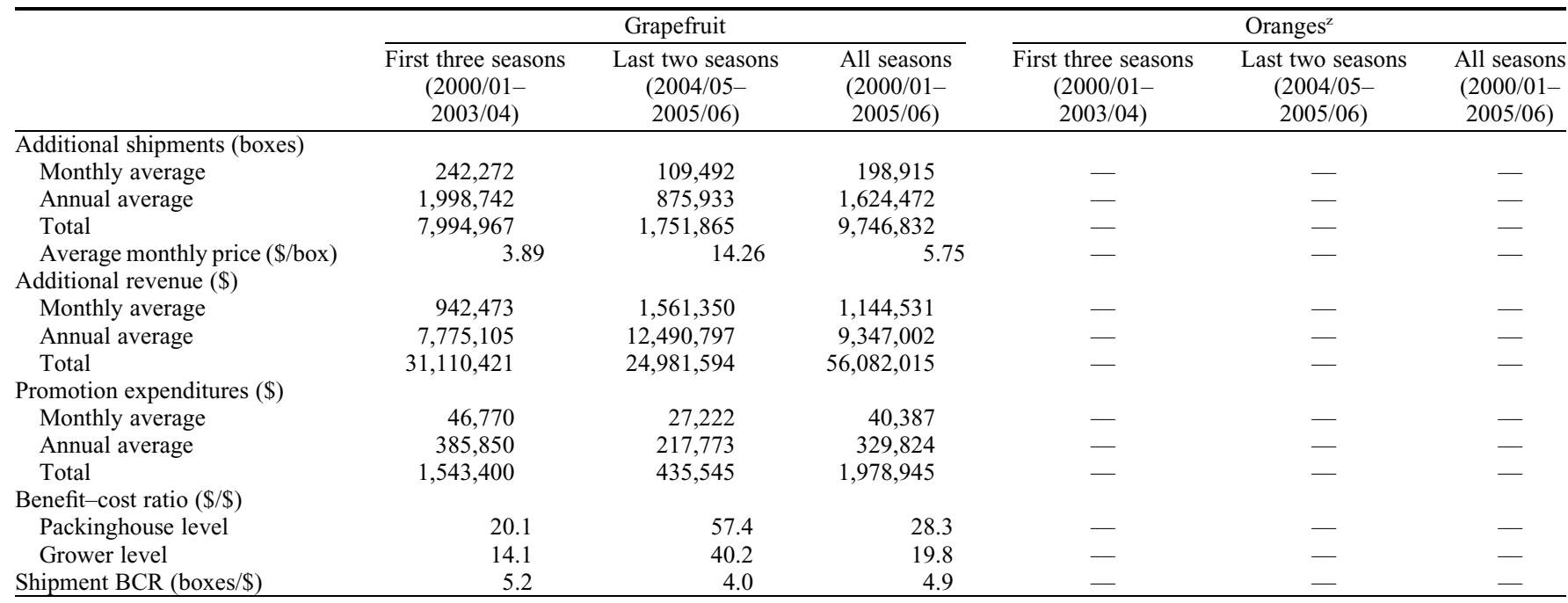

${ }^{2}$ Promotional expenditures were found to have no statistically significant effect on Texas orange shipments.

$\mathrm{BCR}=$ benefit-cost ratio. 
assume that the same promotion expenditure is made in 2 different years and generates exactly the same increase in shipments in both years. However, if the price is higher in the second year as a result of weather problems or other market issues, the calculated BCR will be higher in the second year because the revenue from the shipments will be higher in that year although the number of boxes shipped is the same in both years. For this reason, a "shipment" $\mathrm{BCR}$ is also calculated as the increase in the number of grapefruit boxes shipped [from Eq. (2)] for every dollar spent on promotion:

$$
\text { Shipment BCR }=\frac{\sum_{\mathrm{t}=1}^{\mathrm{T}}\left(\mathrm{C}_{\mathrm{t}}^{\mathrm{A}}-\mathrm{C}_{\mathrm{t}}^{\mathrm{Z}}\right)}{\sum_{\mathrm{t}=1}^{\mathrm{T}} \mathrm{E}_{\mathrm{t}}} \text {. }
$$

Because the price is no longer involved, this measure of $\mathrm{BCR}$ provides a better indication of the cost-effectiveness of the promotion program in expanding shipments of citrus.

Based on Eq. (3), the BCR to Texas grapefruit promotion at the packinghouse level is 28.3 (19.8 at the grower level) (Table 3 ) over the full six-season analysis of the Texas citrus promotion program. In other words, for every dollar spent on promotion over the 2000/01 through 2005/06 period, the return to the Texas grapefruit industry at the packinghouse level was $\$ 28$ in additional revenues $(\$ 20$ at the grower level) from increased shipments of grapefruit. This return is revenue that would not have been earned by the industry had it not been for the Texas citrus promotion program.

Comparing the grapefruit $\mathrm{BCR}$ for the first four seasons (2000/01 through 2003/04) with that of the last two seasons (2004/05 through 2005/06), the calculated BCR jumped dramatically from 20.1 to 57.4 (14.1 to 40.2 at the grower level) despite a reduction in promotion funding during the last two seasons and a reduction in the marginal effectiveness of promotion expenditures (Table 3 ). This result occurs because of the run-up in the average price of grapefruit in the last two seasons. Consequently, a more reasonable measure of the effectiveness of Texas citrus promotion efforts is given by the Shipment BCR [Eq. (4)], which indicates that the increase in the number of boxes of grapefruit shipped per promotion dollar spent dropped from 5.2 in the first three seasons to 4.0 in the last two seasons (Table 3).

Because the number of boxes of grapefruit being added each month to total shipments as a result of promotion [the numerator in Eq. (4)] dropped in the last two seasons of the study period precisely when the funding for citrus promotion also dropped [the denominator in Eq. (4)], one would not necessarily expect that the additional boxes shipped per dollar spent on promotion would fall. Then why did the Shipment BCR drop in the last two seasons of the study period? At least two factors likely worked together to reduce the cost-effectiveness of promotion expenditures during that period. First, during those two seasons, the share of promotion funds allocated to cover administrative costs became larger than the share used for promotion programs as TexaSweet struggled to cover fixed costs and employee salaries to maintain a continuous program despite a drop in total revenues allocated to them by TVCC. The consequence was that for every dollar of assessment funds allocated for promotion, the less the average impact of those dollars on grapefruit shipments.

Second, in the last two to three seasons of the study period, the citrus promotion strategy changed from an historical emphasis on merchandising, advertising, and POP materials to a concentration on public relations as the primary promotional tool. To the extent that the public relations activities funded were less effective than the combination of activities previously funded, the lower the average impact of the funds spent on promotion would have been in the last two to three seasons of the study period.

The BCRs calculated for the Texas citrus promotion program seem high, at least for grapefruit, relative to those generally reported for the larger commodity promotion programs. Reported BCRs for commodity checkoff programs typically range from $\approx 2: 1$ to $10: 1$, although much higher BCRs (from 12:1 up to 50:1 and higher) are not uncommon (Williams and Capps, 2006; Williams and Nichols, 1998). Given the low level of promotion expenditures for Texas citrus compared with the promotion expenditures for the major checkoff commodities like cotton, soybeans, beef, and pork, however, the somewhat higher BCRs found for Texas grapefruit are not unreasonable. The higher BCRs would imply that although Texas citrus promotion efforts have been successful, the promotion activities also are greatly underfunded. Both experience and the theory of advertising suggest strongly that a substantial increase in funding over time would likely reduce the Texas grapefruit BCR to levels more in line with those of the better-funded commodity promotion programs.

\section{Insights for Other Commodity Promotion Programs}

This study finds that Texas citrus promotion programs have effectively enhanced shipments of Texas grapefruit and that the benefits of the promotion efforts in terms of increased grapefruit industry revenues are greater than the costs. The study also finds that the promotion programs have had no statistically discernible effects on Texas orange shipments and, hence, have not generated returns to Texas orange growers. Although specific to the promotion program of Marketing Order 906, these results provide some important insights for the operation and management of other commodity promotion programs, particularly those at the state or regional level:

- Growers in a particular state or region can successfully promote the demand for their products if they are sufficiently differentiated from those produced in other states or regions as in the case of Texas grapefruit. However, funds invested in promoting homogenous, undifferentiated commodities like Texas oranges are unlikely to stimulate a shift in consumer demand for those commodities.

- Even for undifferentiated commodities like Texas oranges, however, advertising can enhance buyer loyalty by reducing their price responsiveness. As a result, a weather-induced run-up in price, for example, is less likely to drive buyers to alternative sources of the product.

- The gains from promotion can dissipate quickly if the marketing order or other commodity promotion group fails to at least maintain its level of promotion funding from year to year.

- How a marketing order or other commodity promotion group chooses to allocate its promotion funds among alternative promotion activities can influence the effectiveness of the funds in enhancing demand. In the case of Marketing Order 906, a shift in promotion strategy away from merchandising to public relations likely contributed to a decline in the effectiveness of promotion activities.

\section{Literature Cited}

Clarke, D.G. 1976. Econometric measurement of the duration of advertising effect on sales. J. Mark. Res. 13:345-357.

Findley, D.F., B.C. Monsell, W.R. Bell, M.C. Otto, and B.-C. Chen. 1998. New capabilities and methods of the X-12-ARIMA Seasonal Adjustment Program (with discussion). J. Bus. Econ. Stat. 16:127-176.

Forker, O.D. and R.W. Ward. 1998. Commodity advertising: The economics and measurement of generic programs. Lexington Books, New York, NY.

Jacobs, J.A. 1994. Cooperatives in the U.S. citrus industry. Rural Business and Cooperative Development Service, U.S. Department of Agriculture, Washington, DC.

Lee, J.Y. and M.G. Brown. 1992. Lag structures in commodity advertising research. Agribusiness 8:143-154.

Pagán, J.A., S. Sethi, and G.A. Soydemir. 2001. The impact of promotion/advertising expenditures on citrus sales. Appl. Econ. Lett. 8:659663.

Sauls, J.W. 2002. Rootstock and scion varieties. Texas Cooperative Extension, Texas Citrus and Subtropical Fruits, Horticulture Department, Texas A\&M University. 15 Feb. 2007. <http:// aggie-horticulture.tamu.edu/citrus/cultivars/ L2304.htm>.

U.S. Department of Agriculture. 2006a. Citrus fruits: 2006 summary. Report No. Fr Nt 3-1 (06). Agricultural Statistics Board, National Agricultural 
Statistics Service, Washington, DC. 15 Feb. 2007. <http://usda.mannlib.cornell.edu/usda/ nass/CitrFrui//2000s/2006/CitrFrui-09-21-2006. pdf $>$.

U.S. Department of Agriculture. 2006b. Marketing Order 906: Texas oranges and grapefruit. Agricultural Marketing Service. 16 Feb. 2007. $<$ https://www.ams.usda.gov/fv/mocommodities/ 906.htm>.

U.S. Government Printing Office. 2007. Title 7: Agriculture, Part 906. Electronic Code of Fed- eral Regulations. GPO Access. 12 Feb. 2007 $<$ http://ecfr.gpoaccess.gov/cgi/t/text/text-idx?sid= $723 f 9 b 46996912 f 506 c 305 c 671972887 \& c=e c f r \&$ tpl=/ecfrbrowse/Title07/7tab_02.tpl $>$.

Williams, G.W. and O. Capps, Jr. 2006. Measuring the effectiveness of checkoff programs. Choices 21:73-78.

Williams, G.W. and J.P. Nichols. 1998. Effectiveness of commodity promotion. Texas Agricultural Market Research Center Consumer and Product Research Report No. CP1-
98. Texas A\&M University, College Station, TX.

Williams, G.W., C.R. Shumway, and H.A. Love. 2002. Returns to soybean producers from investments in promotion and research. Agricultural and Resource Economics Review 31:97-111.

Zellner, A. 1962. An efficient method of estimating seemingly unrelated regressions and tests for aggregation bias. J. Am. Stat. Assoc. 57:348368 . 